\title{
Simulation and experiment on thermal performance of a micro-channel heat pipe under different evaporator temperatures and tilt angles
}

Guiqiang $\mathrm{Li}^{\mathrm{a}}$, *

Guiqiang.Li@hull.ac.uk

Thierno M.O. Diallo

Yousef Golizadeh Akhlaghi

Samson Shittu

Xudong Zhao

Xiaoli Ma

Yingfeng Wang (Revised to "Yinfeng Wang"), *

Guiqiang.Li@hull.ac.uk

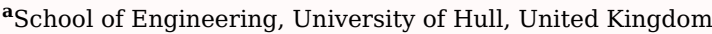

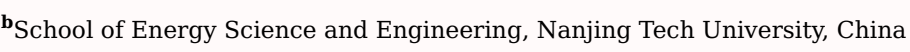

${ }^{*}$ Corresponding author.

Abstract

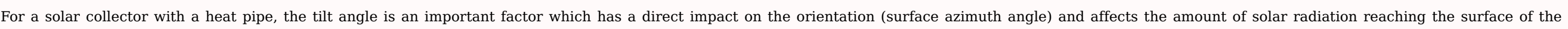

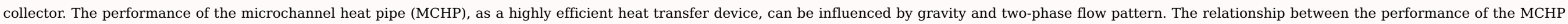

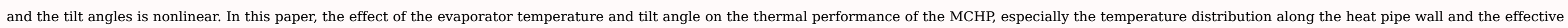

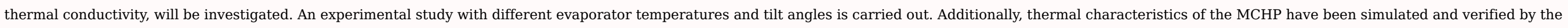

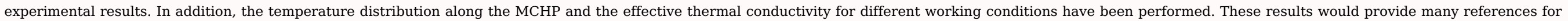
the solar collector with MCHP system design, optimization, and installation

Keywords: Solar energy; Microchannel heat pipe; Tilt angle; Thermal conductivity; Heat transfer

\section{Introduction}

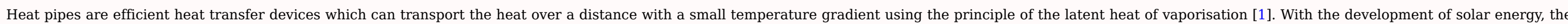

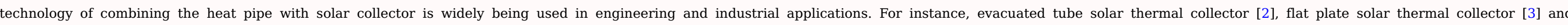

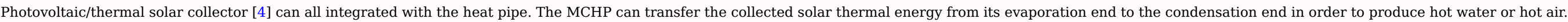

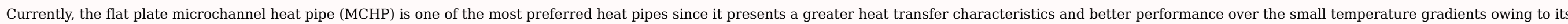

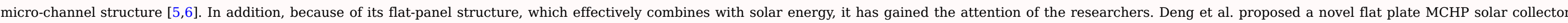

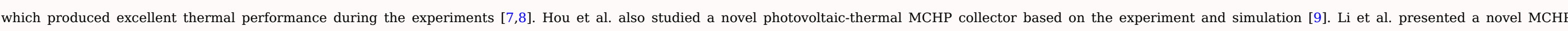

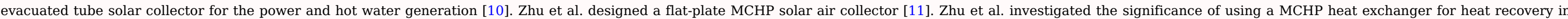




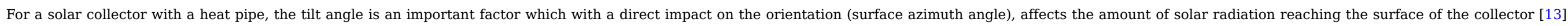

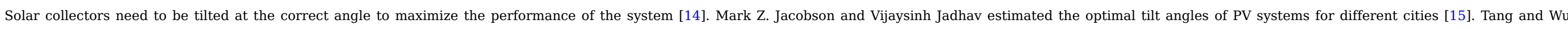
optimized the tile angle of solar collector in China [16]. Huseyin Gunerhan and Arif Hepbasli indicated the optimum tilt angle of solar collectors for building applications [17].

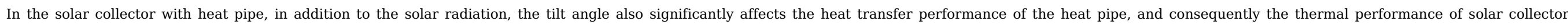

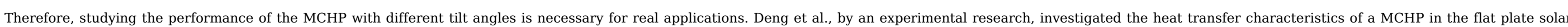

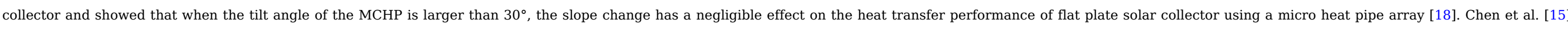

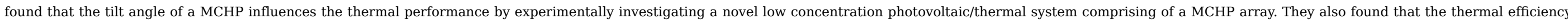

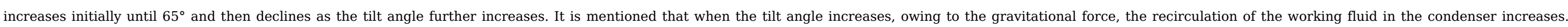

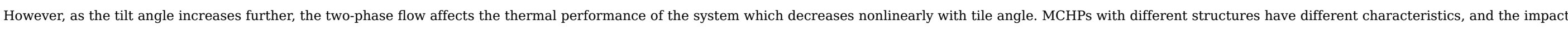

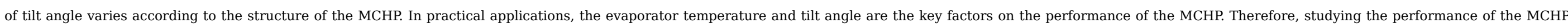

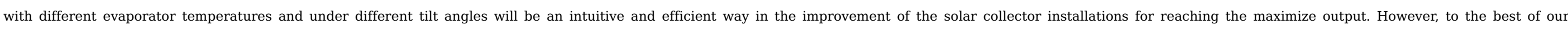

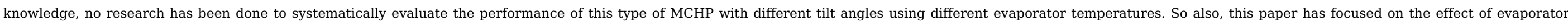
temperature of a MCHP for solar collector application.

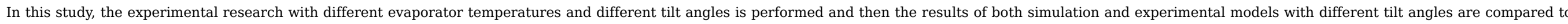

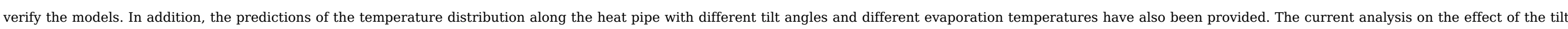
angle would provide a valuable reference for studying, optimization and implementation of the solar collectors with MCHP.

\section{Description of a MCHP}

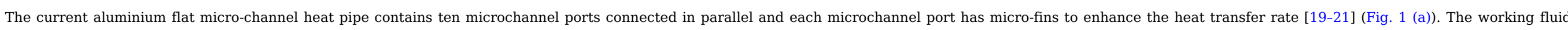

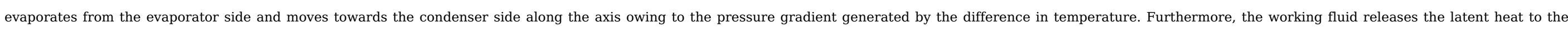

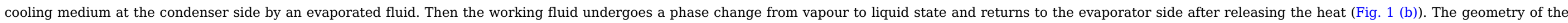
system is shown in Fig. 1.

\section{(C2019, Elsevier. This manuscript version is made available under the CC-BY-NC-ND 4.0 license http://creativecommons.org/licenses/by-nc-nd/4.0/}




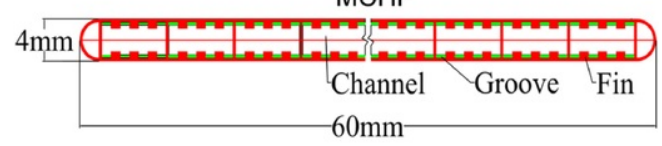

(a)

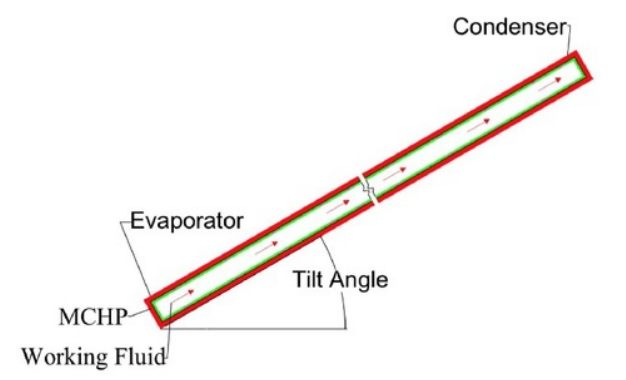

(b)

Fig. 1 Schematic diagram of MCHP.

alt-text: Fig. 1

\section{Micro-channel heat pipe simulation}

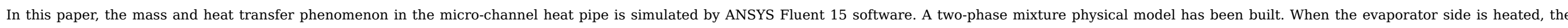
phase change from the liquid to the vapour occurs during the boiling of the nucleate pool in the evaporator section.

\subsection{Model theory}

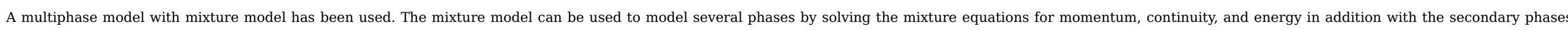

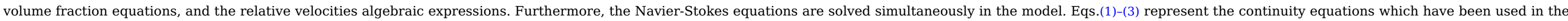
simulation of the system,

$\frac{\partial\left(\rho_{m}\right)}{\partial t}+\nabla \cdot\left(\rho_{m} \vec{v}_{m}\right)=0$

where $\vec{v}_{m}$ is the velocity of the mass-average,

$\vec{v}_{\mathrm{m}}=\frac{\sum_{\mathrm{k}=1}^{\mathrm{n}} \alpha_{\mathrm{k}} \rho_{\mathrm{k}} \overrightarrow{\mathrm{v}}_{\mathrm{k}}}{\rho_{\mathrm{m}}} \overrightarrow{\mathrm{v}}_{\mathrm{m}}=\frac{\sum_{\mathrm{k}=1}^{\mathrm{n}} \alpha_{\mathrm{k}} \rho_{\mathrm{k}} \overrightarrow{\mathrm{v}}_{\mathrm{k}}}{\rho_{\mathrm{m}}}$

and

$\rho_{m}=\sum_{k=1}^{n} \alpha_{k} \rho_{k}$

$\rho_{m}$ is the density of the mixture, $\alpha_{k}$ is the phase $\mathrm{k}$ volume fraction.

Eq. (4) is the momentum equation which is formed by summing up all the individual momentum equations for all phases. 
$\frac{\partial\left(\rho_{\rho} \vec{v}_{m}\right)}{\partial t}+\nabla \cdot\left(\rho_{m} \vec{v}_{m} \vec{v}_{m}\right)=$
$-\nabla \mathrm{p}+\nabla \cdot\left[\mu_{m}\left(\nabla \vec{v}_{m}+\nabla \vec{v}_{m}^{T}\right)\right]+\rho_{m} \vec{g}+\vec{F}+\nabla \cdot\left(\sum_{k=1}^{n} \alpha_{k} \rho_{k} \vec{v}_{d r, k} \vec{v}_{d r, k}\right)$

where $\mathrm{n}$ is the phases number, $\vec{F}$ is a body force, and $\mu_{m}$ is the viscosity of the mixture: $\mu_{m}=\sum_{k=1}^{n} \alpha_{k} \mu_{k} . \vec{v}_{d r k, k}$, if the drift velocity for secondary phase $\mathrm{k}, \vec{v}_{d r, k}=\vec{v}_{k}-\vec{v}_{m}$.

The energy equation is expressed as Eq. (5).

$$
\frac{\partial}{\partial t} \sum_{k=1}^{n}\left(\alpha_{k} \rho_{k} E_{k}\right)+\nabla \cdot \sum_{k=1}^{n}\left(\alpha_{k} \vec{v}_{k}\left(\rho_{k} E_{k}+p\right)\right)=\nabla \cdot\left(k_{e f f} \nabla T\right)+S_{E}
$$

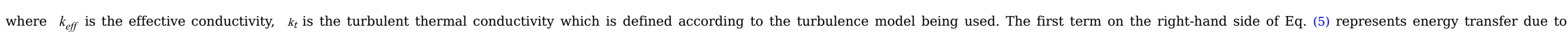
conduction and $S_{E}$ includes any other volumetric heat sources. In Eq. (5) the values of $\mathrm{E}_{\mathrm{k}}$ has been calculated as:

$\left\{\begin{array}{c}E_{k}=h_{k}-\frac{p}{\rho_{k}}+\frac{v_{k}^{2}}{2}, \text { for a compressible phase } \\ E_{k}=h_{k}, \text { for an incompressible phase }\end{array}\right.$

where $h_{k}$ is the sensible enthalpy for phase $k$.

Equation (7) (8) is used with the Mixture model for the interphase mass transfer through evaporation-condensation.

The evaporation occurs when $\mathrm{T}>\mathrm{T}_{\text {sat }}$, wherein the mass transfer, $\dot{m}_{1 v}$., can be described as

$$
\dot{m}_{1 v}=0.1 * \alpha_{l} \rho_{l} \frac{\left(T-T_{\text {sat }}\right)}{T_{\text {sat }}}
$$

The condensation occurs when $\mathrm{T}<\mathrm{Tsat}$, wherein the mass transfer, $\dot{m}_{v l}$, can be described as

$$
\dot{m}_{v l}=0.1 * \alpha_{l} \rho_{l} \frac{\left(T-T_{\text {sat }}\right)}{T_{\text {sat }}}
$$

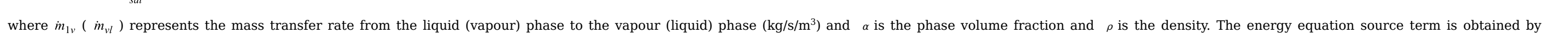
the multiplication of the mass transfer rate and the latent heat.

$T>T_{s a t} \quad S_{E 1}=\dot{m}_{e \rightarrow v, 1 l v} L H$

$\begin{array}{ll}T<T_{\text {sat }} & S_{E 1}=\dot{m}_{e \rightarrow v, 2 v l} L H\end{array}$

where LH is the latent heat vaporisation.

\subsection{Geometry and operating conditions of the model}

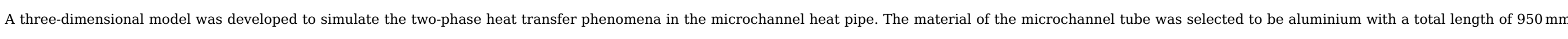

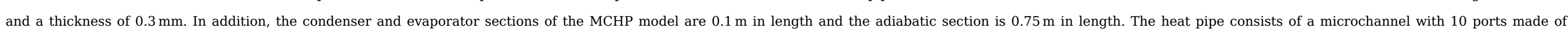

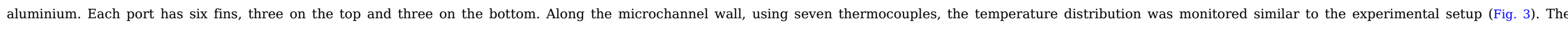

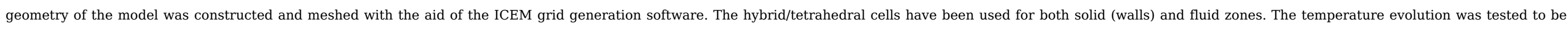
independent to the mesh size. Note a total of more than 2,000,000 cells were used in this model. This cell number was limited by the software for present work.

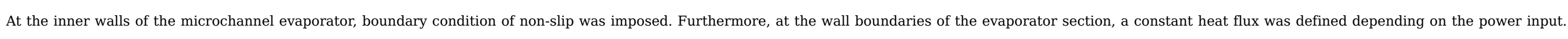
While at the adiabatic section and condenser section a boundary condition of zero heat flux was defined (Fig. 2). 


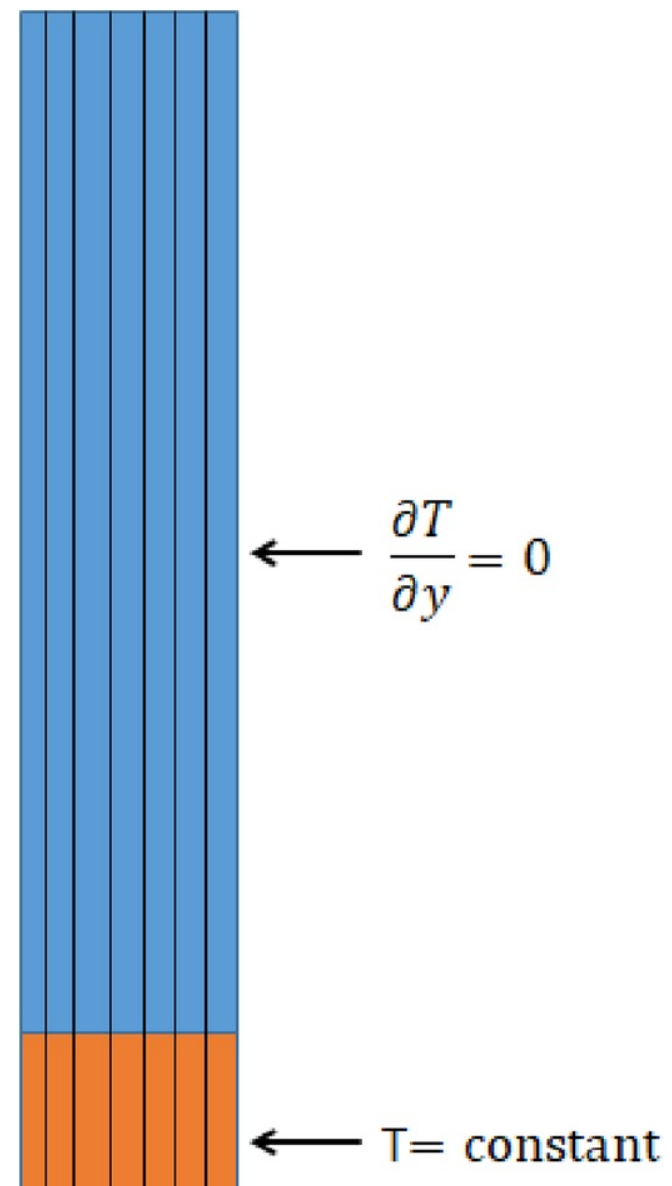

Fig. 2 Boundary conditions (Size: $95 \mathrm{~cm} * 6 \mathrm{~cm}$ )

alt-text: Fig. 2 


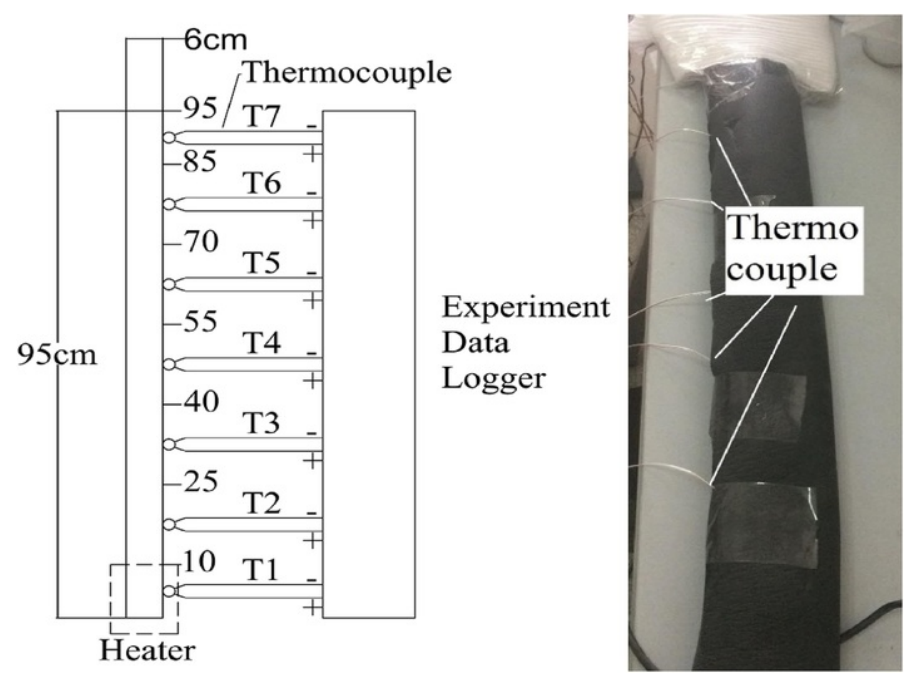

Fig. 3 Test sketch of experiment.

\section{alt-text: Fig. 3}

\subsection{Model settings}

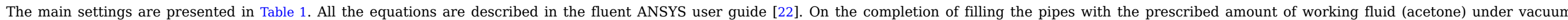

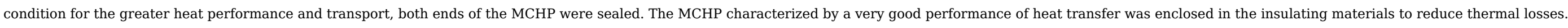

Table 1 Model parameters.

alt-text: Table 1

\begin{tabular}{|c|c|c|c|}
\hline Model Setting & Parameter & Model Setting & Parameter \\
\hline Heat pipe wall & Aluminium & Solver & Pressure-based Steady state \\
\hline $\begin{array}{l}\text { Working Fluid } \\
\text { Filling ratio }\end{array}$ & $\begin{array}{l}\text { Mixture (acetonevapour/acetoneliquid) } \\
1 / 3\end{array}$ & Viscous & k-e model. \\
\hline Model & Multiphase model with mixture (evaporation/condensation model) & Solution method & Pressure-velocity coupling (coupled), Momentum, volume fraction and energy discretization (Quick method) \\
\hline
\end{tabular}

\section{Comparison of the simulation and experimental results}

\subsection{Experiment detail}

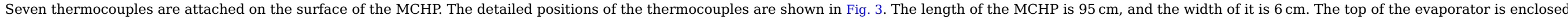

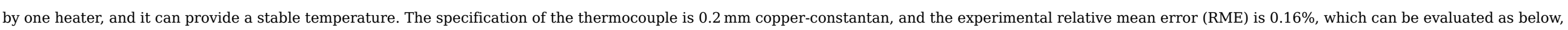

$\mathrm{RME}=\frac{\sum_{1}^{N} \frac{\Delta T}{T}}{N}$

\subsection{Comparison and verification}

The relative error (RE) between simulation values and experimental results can be calculated by: 
where $\mathrm{X}_{\mathrm{sim}}$ and $\mathrm{X}_{\mathrm{exp}}$ are the simulation and experimental values, respectively.

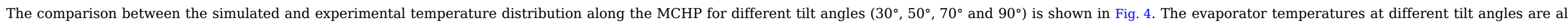

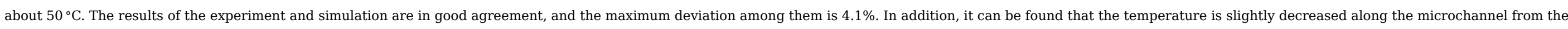
evaporator side to the condenser side, but the temperature decrease varies for different tilt angles, which indicates that the tilt angle affects the heat transfer performance of MCHP.

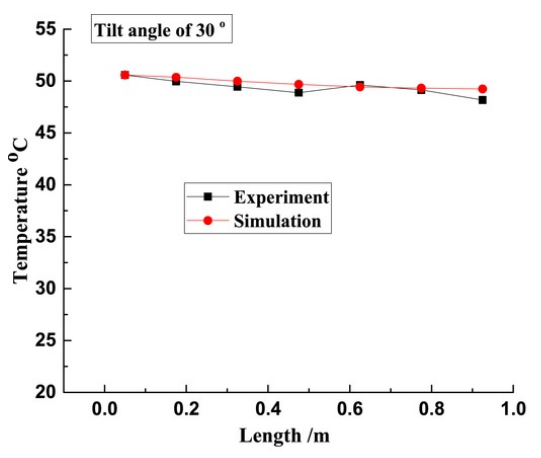

(a)

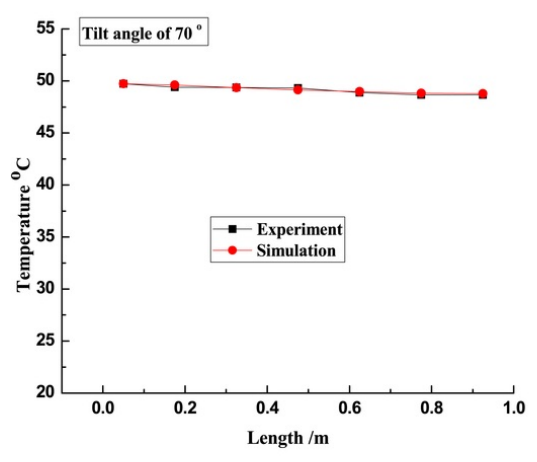

(c)

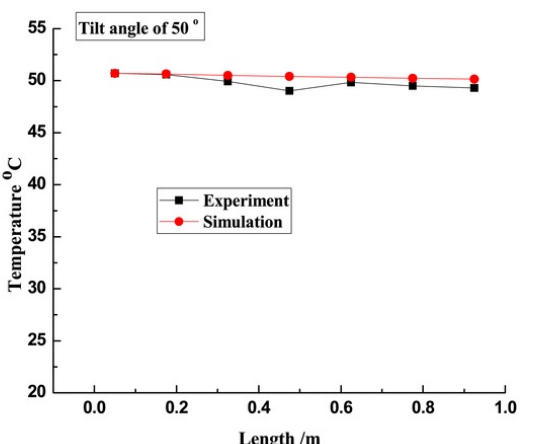

(b)

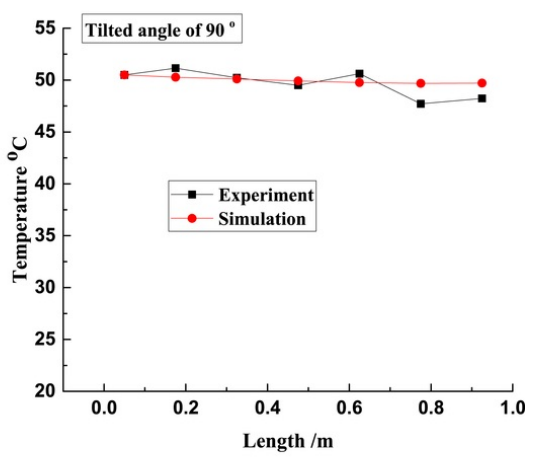

(d)

Fig. 4 Wall temperature comparison between simulation and experiment.

alt-text: Fig. 4

\section{Performance prediction and analysis}

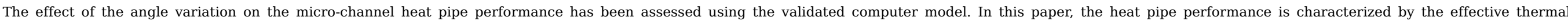
conductivity. The effective thermal conductivity of the microchannel heat pipe, $\mathrm{k}_{\mathrm{eff}}$, can be calculated as follows:

$$
\mathrm{k}_{\mathrm{eff}}=\frac{\mathrm{Q}_{\mathrm{in}} \mathrm{L}_{\mathrm{eff}}}{A(\Delta T)}
$$

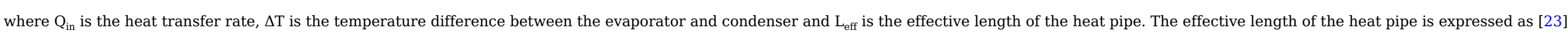


where, $\mathrm{L}_{\mathrm{e}}, \mathrm{L}_{\mathrm{a}}$ and $\mathrm{L}_{\mathrm{c}}$ are the lengths of evaporator, adiabatic and condenser sections of heat pipe.

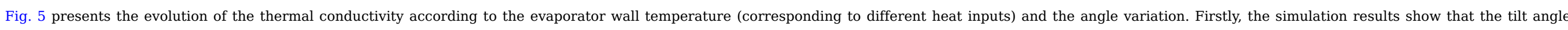

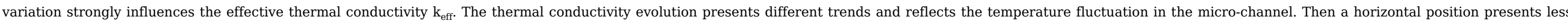

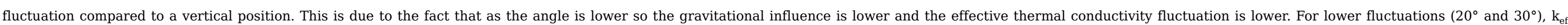

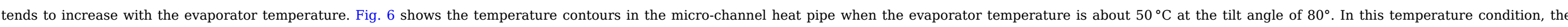

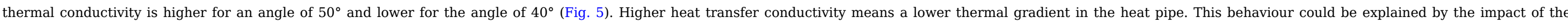
gravity on the flow pattern according to the tilt angle. The average thermal conductivity shows that the heat pipe is better for a tilt angle of $50^{\circ}$, followed by $70^{\circ}$, $90^{\circ}$, etc.

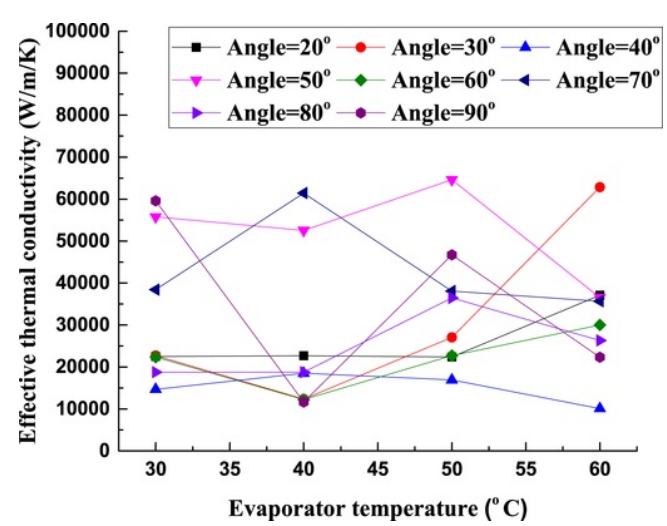

Fig. 5 Influence of evaporator temperature and the tilt angle on the effective thermal conductivity. 


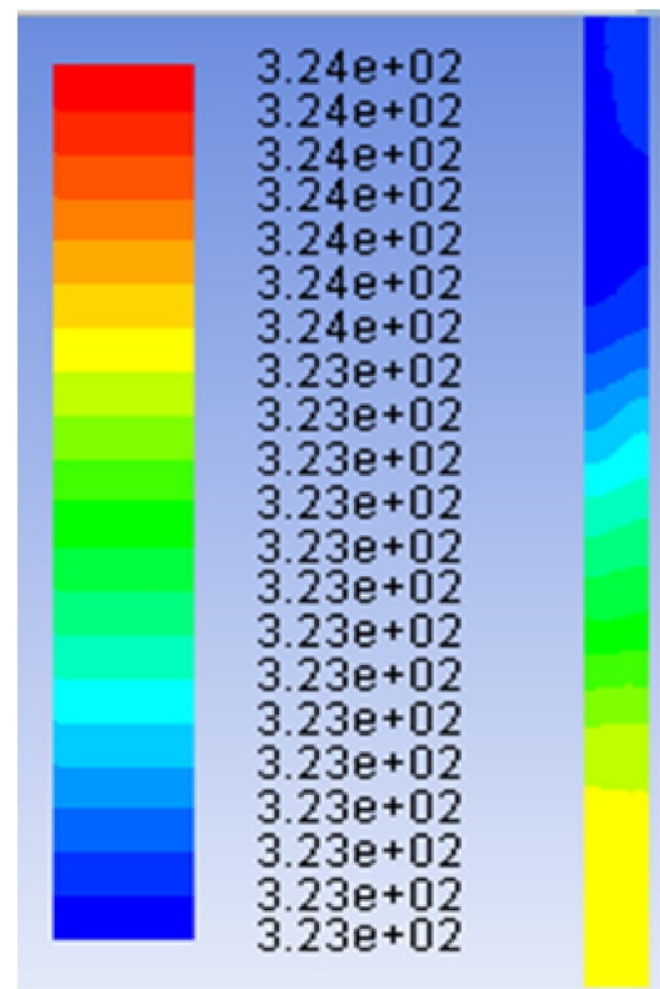

Fig. 6 Contours of the temperature (K) (Size: $95 \mathrm{~cm} * 6 \mathrm{~cm}$ ) alt-text: Fig. 6

\subsection{Effect of different tilt angles}

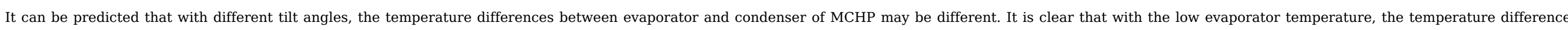

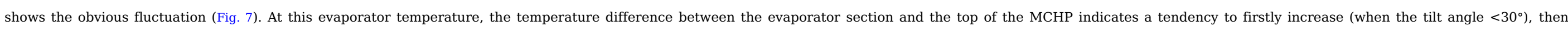

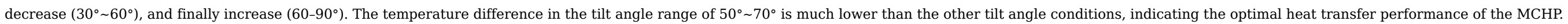




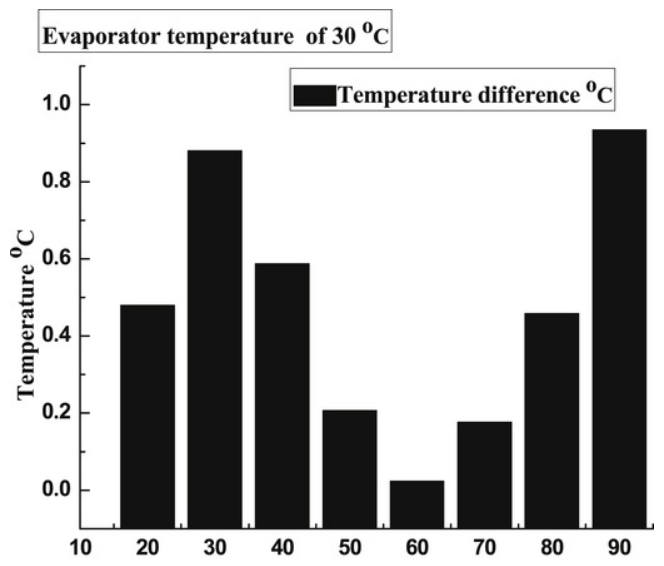

Tilt angle 0

Fig. 7 Temperature difference between evaporator and condenser of MCHP with different tilt angle at the evaporator temperature of $30^{\circ} \mathrm{C}$.

alt-text: Fig. 7

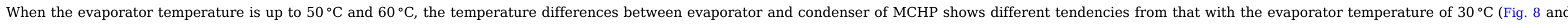

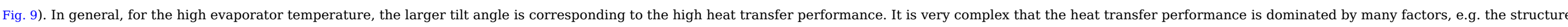

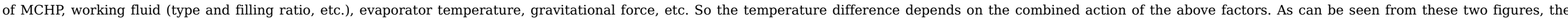
minimum temperature difference both occur at the tilt angle of $50^{\circ}$, which represent the best heat transfer performance of the MCHP.

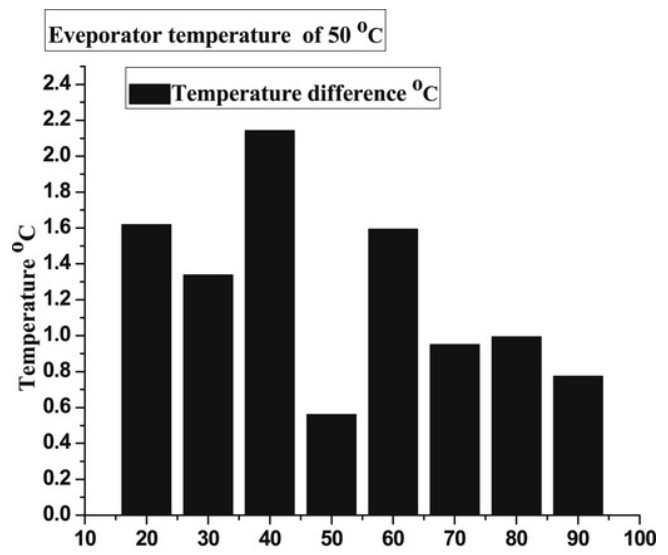

Fig. 8 Temperature difference between evaporator and condenser of MCHP) with different tilt angle at the evaporator temperature of $50^{\circ} \mathrm{C}$.

alt-text: Fig. 8 


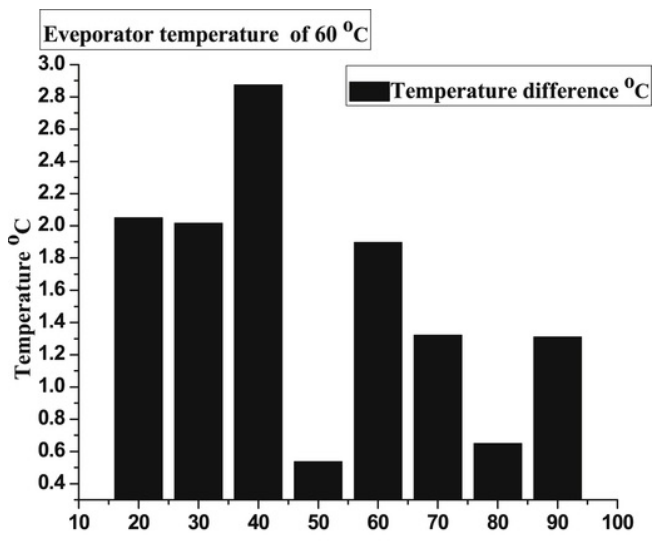

Tilt angle ${ }^{0}$

Fig. 9 Temperature difference between evaporator and condenser of MCHP with different tilt angle at the evaporator temperature of $60^{\circ} \mathrm{C}$

alt-text: Fig. 9

\subsection{Effect of different evaporator temperatures}

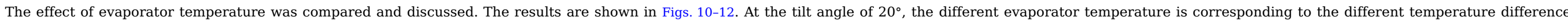

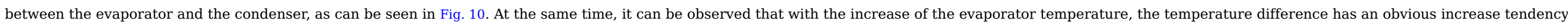

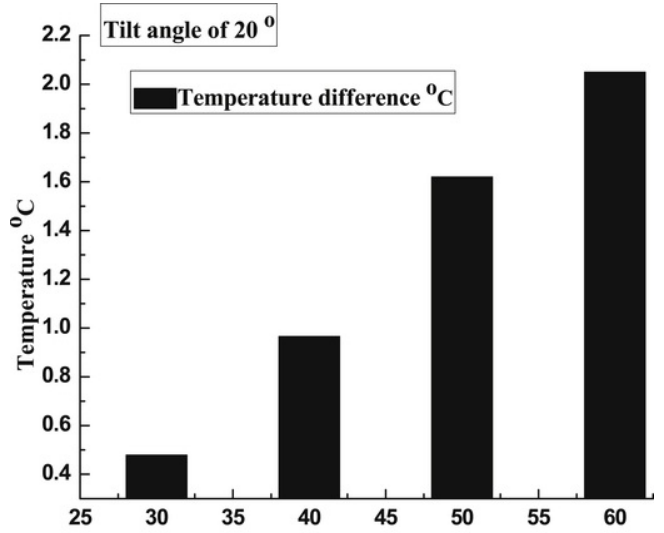

Eveporator temperature ${ }^{0} \mathrm{C}$

Fig. 10 Temperature difference between evaporator and condenser of MCHP with different evaporator temperature at tilt angle of $20^{\circ}$.

alt-text: Fig. 10 


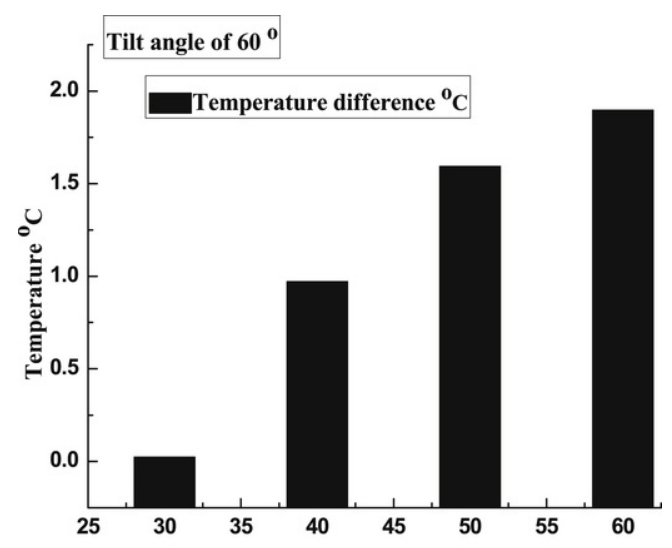

Eveporator temperature ${ }^{0} \mathrm{C}$

Fig. 11 Temperature difference between evaporator and condenser of MCHP with different evaporator temperature at tilt angle of $60^{\circ}$

alt-text: Fig. 11

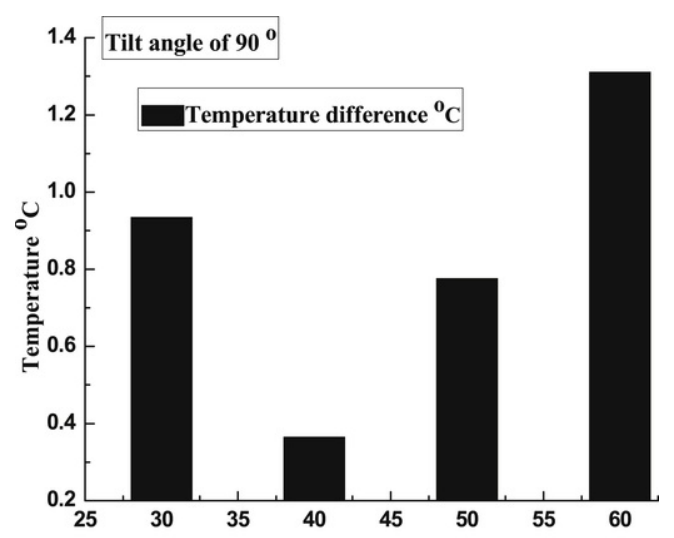

Eveporator temperature ${ }^{\circ} \mathrm{C}$

Fig. 12 Temperature difference between evaporator and condenser of MCHP with different evaporator temperature at tilt angle of $90^{\circ}$.

\section{alt-text: Fig. 12}

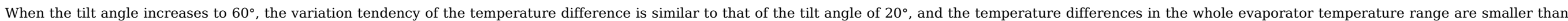
that of the tilt angle of $20^{\circ}$. However, the nonlinear trend of temperature difference variation with the different evaporator temperature is more clear when the tilt angle increases.

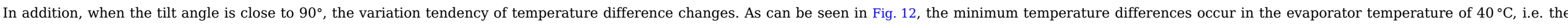

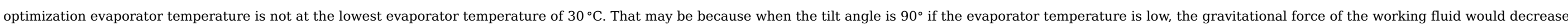
the heat transfer performance.

\section{Conclusion}

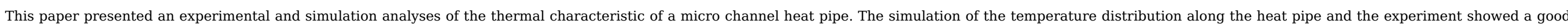

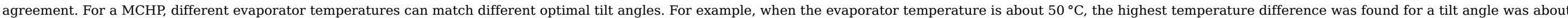


$40^{\circ}$ in most cases. With tilt angle of $50^{\circ}$, the temperature gradient was found lower (which means better heat transfer performance for MCHP)

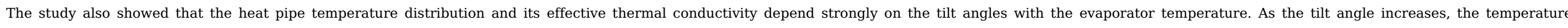

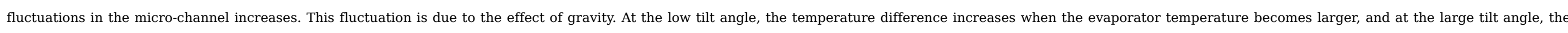

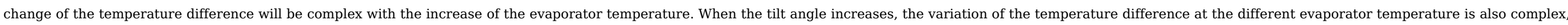
which does not show the obvious tendency, but it can also be seen that the optimization tilt angle is at the middle tilt angles $\left(50^{\circ} \sim 70^{\circ}\right)$ for different evaporator temperature.

\section{Acknowledgment}

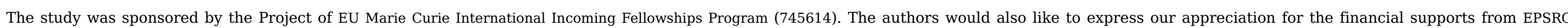

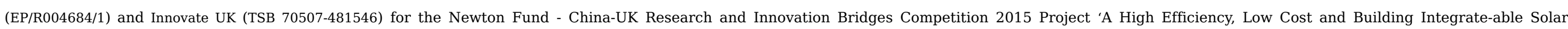
Photovoltaic/Thermal (PV/T) system for Space Heating, Hot Water and Power Supply' and DongGuan Innovation Research Team Program (No. 2014607101008).

\section{References}

[1] G. Li, X. Zhao and J. Ji, Conceptual development of a novel photovoltaic-thermoelectric system and preliminary economic analysis, Energy Convers Manag 126, 2016 , 935-943.

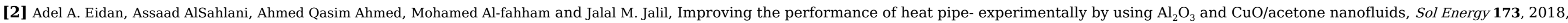
$780-788$.

[3] Lingjiao Wei, Dazhong Yuan, Dawei Tang and Bangxian Wu, A study on a flat-plate type of solar heat collector with an integrated heat pipe, Sol Energy 97, 2013 , 19-25.

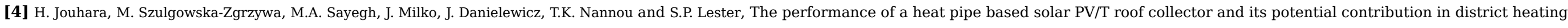
applications, Energy 136, 2017, 117-125.

[5] G. Li, W. Feng, Y. Jin, X. Chen and J. Ji, Discussion on the solar concentrating thermoelectric generation using micro-channel heat pipe array, Heat Mass Transf 53 (11), 2017, 3249-3256.

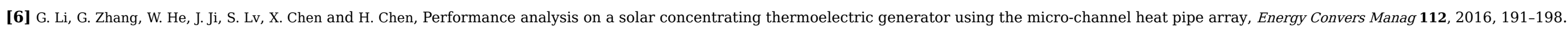

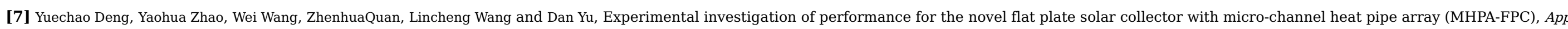
Therm Eng 54 (2), 2013, 440-449.

[8] Yuechao Deng, Wei Wang, Yaohua Zhao, Liang Yao and Xinyue Wang, Experimental study of the performance for a novel kind of MHPA-FPC solar water heater, Appl Energy 112, 2013, 719-726.

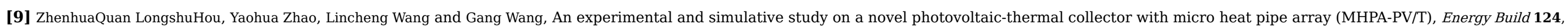
2016, 60-69.

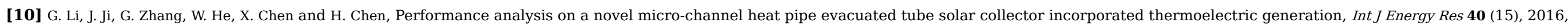
2117-2127.

[11] Tingting Zhu, Yanhua Diao, Yaohua Zhao and Ma Cheng, Performance evaluation of a novel flat-plate solar air collector with micro-heat pipe arrays (MHPA), Appl Therm Eng 118, 2017 , 1-16.

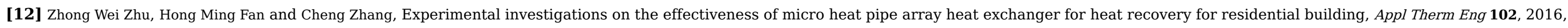
980-988.

[13] Kamal Skeiker, Optimum tilt angle and orientation for solar collectors in Syria, Energy Convers Manag 50, 2009, 2439-2448.

[14] Adnan Shariah, M-Ali Al-Akhras and I.A. Al-Omari, Optimizing the tilt angle of solar collectors, Renew Energy 26, 2002, 587-598.

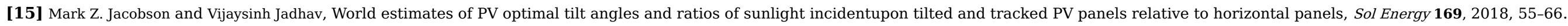


[16] Huseyin Gunerhan and Arif Hepbasli, Determination of the optimum tilt angle of solar collectors for building applications, Build Environ 42, 2007 , 779-783.

[17] Runsheng Tang and Tong Wu, Optimal tilt-angles for solar collectors used in China, Appl Energy 79, 2004, 239-248.

[18] Xue Z., Qu W. Experimental study on effect of tilt angles to ammonia pulsating heat pipe. Chin J Aeronaut, 27(5): 1122-1127.

[19] Lingen Chen and Huijun Feng, Multi-objective constructal optimizations for fluid flow, heat and mass transfer processes, 2017, Science Press; Beijing.

[20] Huijun Feng, Lingen Chen and Shaojun Xia, Constructal design for disc-shaped heat exchanger with maximum thermal efficiency, Int J Heat Mass Transf 130, 2019 , 740-746.

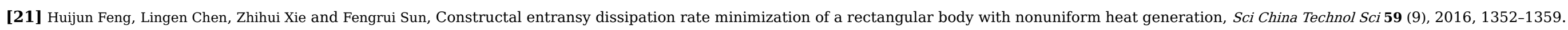

[22] ANSYS Fluent, Ansys fluent theory guide: version 13.0, 2010, Ansys Inc.; Canonsburg.

[23] A. Brusly Solomon, M. Sekar and S.H. Yang, Analytical expression for thermal conductivity of heat pipe, Appl Therm Eng 100, 2016, $462-467$.

\section{Nomenclature}

F: body force $\left[\mathrm{N} / \mathrm{m}^{3}\right]$

h: sensible enthalpy [J/kg]

k: effective conductivity $[\mathrm{W} / \mathrm{m} / \mathrm{K}]$

LH: Latent Heat $[\mathrm{J} / \mathrm{kg}]$

$\mathrm{m}$ : mass $[\mathrm{kg}]$

p: pressure $[\mathrm{Pa}]$

S: volumetric heat source $\left[\mathrm{W} / \mathrm{m}^{3}\right]$

t: time [s]

$\mathrm{v}$ : velocity $[\mathrm{m} / \mathrm{s}]$

$\mathrm{y}$ : dimension $[\mathrm{m}]$

Subscripts

c: condenser

dr: drift

e: evaporator

eff: effective conductivity

k: phase liquid or vapour

l: liquid

m: mixture

$\mathrm{n}$ : number of phase sat saturation

t: turbulent

v: vapour

Greek Symbols

$\rho$ : density $\left(\mathrm{kg} / \mathrm{m}^{3}\right)$

$\alpha$ : volume fraction [-]

$\vec{v}_{m}$ : velocity $[\mathrm{m} / \mathrm{s}]$ 


\section{$\mu$ : dynamic viscosity [Pa.s]}

\section{Queries and Answers}

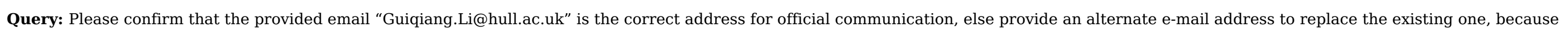
private e-mail addresses should not be used in articles as the address for communication.

Answer: Correct Email address of Yinfeng Wang should be revised to: wangyf@njtech.edu.cn

Query: Please check the author given name and surname.

Answer: The name of this one corresponding author, "Yingfeng Wang", should be revised to "Yinfeng Wang"

Query: Have we correctly interpreted the following funding source(s) and country names you cited in your article: Innovate UK, United Kingdom; EPSRC, United Kingdom?

Answer: Yes

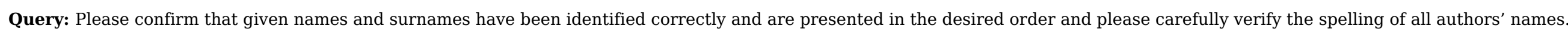

Answer: The given name "Yingfeng" in the author list should be revised to "Yinfeng"

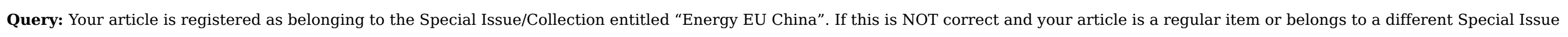
please contact s.venkiteswaran@elsevier.com immediately prior to returning your corrections.

Answer: Yes 